\title{
Apolo: Versão Digital de um Jogo de Tabuleiro para Apoio ao Ensino na Educação Básica
}

\section{Marcus Vinicius Cardoso de Melo ${ }^{1}$, Tiago Henrique Faccio Segato ${ }^{1}$, Jaline Gonçalves Mombach ${ }^{1}$}

\author{
${ }^{1}$ Instituto de Educação, Ciência e Tecnologia de Brasília - Campus Brasília \\ Setor de Grandes Áreas Norte 610 - Asa Norte - 70830-450 - Brasília - DF - Brasil \\ marcuscardoso.sh@gmail.com \\ \{tiago.segato, jaline.mombach\}@ifb.edu.br
}

\begin{abstract}
Good learning requires the interest and motivation of the student to learn. Traditional learning methods do not seem enough for such engagement, and so games are relevant teaching strategies. In this context, we propose the development of a digital game inspired by the Brazilian classic board game, known as "Perfil ". As a methodology, Progressive Web Apps, and a case study in Geography subject is used for high school students. As a result, the game is already available to the public in beta version, and preliminary assessments of students and teachers indicate good acceptance.
\end{abstract}

Resumo. Uma boa aprendizagem requer interesse e motivação do aluno para aprender. Os métodos tradicionais de aprendizado não parecem suficientes para tal engajamento e por isso os jogos são relevantes estratégias de ensino. Nesse contexto, este trabalho propõe o desenvolvimento de um jogo digital inspirado no clássico jogo de tabuleiro "Perfil". Como metodologia, adota-se Progressive Web Apps e o estudo de caso na área de Geografia, com alunos do Ensino Médio. Como resultados, o jogo já está disponível ao público em fase beta, e as avaliações preliminares de alunos e professores indicam boa aceitação.

\section{Introdução}

A falta de motivação dos alunos aos estudos é um dos fatores que dificulta o processo de aprendizagem em sala de aula. Pesquisas mostram que, entre 2016 e 2017, aumentou o número de jovens brasileiros, entre 15 e 29 anos, que não estavam na escola ou no trabalho, chegando a 25,1 milhões. Entre as razões identificadas, 20,1\% desses jovens mencionaram a falta de interesse aos estudos [PNAD 2018]. Logo, manter o engajamento dos estudantes é uma temática desafiadora nas escolas e os professores têm discutido cada vez mais estratégias para tornar as atividades letivas mais agradáveis.

Os Parâmetros Curriculares Nacionais (PCN) e as Orientações Curriculares Nacionais $(\mathrm{OCN})$ evidenciam que o ensino deve ser trabalhado em sala de aula de forma mais dinâmica e divertida, mudando o paradigma da aula tradicional e desenvolvendo a capacidade afetiva e as relações interpessoais, permitindo ao aluno colocar-se no ponto de vista do outro, refletindo, assim, sobre os seus próprios pensamentos. No Ensino Médio, especificamente, os PCN consideram importante a diversificação dos recursos e materiais didáticos tais como experimentos, dinâmicas, software e jogos [BRASIL. Ministério da Educação. Secretaria de Educação Média e Tecnológica 2002]. 
Nesse sentido, o uso da tecnologia na educação tem procurado melhorar a qualidade de ensino no Brasil, uma prova disso é a criação do Centro Nacional de Mídias da Educação (CNME) que tem como proposta o ensino presencial mediado por tecnologia. Com foco no Ensino Médio, o projeto visa criar ambientes de interação nas escolas para que os alunos possam assistir e debater conteúdos on-line, além de explorarem objetos de aprendizagem. Porém, essa proposta depende de parcerias com os estados e, atualmente, está disponível em apenas 150 escolas [CNME 2019]. Desta forma, uma maneira de outras escolas se beneficiarem dos conteúdos é por meio da Plataforma Integrada de Recursos Educacionais Digitais (RED) ${ }^{1}$, que incentiva o envio de recursos por professores para que sejam compartilhados em rede.

A fim de contribuir para a distribuição de recursos educacionais digitais no ensino básico brasileiro, este trabalho apresenta um jogo digital, inspirado no jogo de tabuleiro "Perfil"2 como ferramenta de auxílio a aprendizagem e de interação entre professores e alunos. Com foco inicial no Ensino Médio, foi desenvolvido em Progressive Web App (PWA), tendo em versão beta disponível para testes. Como estudo de caso, aplicou-se em um cenário com professores de Geografia e em uma turma de $2^{\circ}$ ano do ensino médio do Instituto Federal de Brasília.

$\mathrm{O}$ artigo está organizado como segue. Na Seção 2, apresenta-se o referencial teórico sobre uso de jogos em sala de aula. Na Seção 3, explica-se o jogo de tabuleiro e alguns trabalhos relacionados. Na Seção 4, detalha-se o método de desenvolvimento e aplicação do jogo Apolo, bem como as tecnologias usadas. Na Seção 5, descreve-se os resultados preliminares obtidos a partir da aplicação em uma turma. Por fim, a Seção 6 discute as considerações finais.

\section{Referencial Teórico}

O processo de aprendizagem envolve diversos fatores sociais, culturais e psicológicos. Pode-se identificar três tipos gerais de aprendizagem: a cognitiva, que resulta no armazenamento organizado de informações na mente do ser que aprende; a afetiva, que resulta de sinais internos ao indivíduo, podendo ser identificada com experiências, tais como: prazer e dor, satisfação e descontentamento, alegria e ansiedade; e a psicomotora, que envolve respostas musculares adquiridas por meio de treino e prática. A aprendizagem faz parte do processo educativo, sendo elementar para a transmissão do conteúdo, acontecendo de uma forma natural [Rogers et al. 1972].

Para que os objetivos da aprendizagem sejam alcançados, é necessário, primeiramente, o interesse e motivação do aluno. A motivação é um processo que se dá no interior do sujeito, estando intimamente ligado às relações de troca que o mesmo estabelece com o meio, principalmente com seus professores e colegas [Ryan and Deci 2000]. Nesse sentido, é preciso que os métodos de aprendizagem sejam capazes de despertar o interesse do aluno. Uma das formas de despertar o interesse do aprendiz é utilizar métodos lúdicos no processo de aprendizagem. Em consonância a isso, o jogo é uma das atividades que ativa a parte cognitiva, afetiva e psicomotora do aluno.

A utilização de jogos como ferramenta de aprendizagem é antiga. Platão já acreditava na ação dos jogos educacionais ao ensinar seus "discípulos" através de jogos com pa-

\footnotetext{
${ }^{1}$ Disponível em ¡https://plataformaintegrada.mec.gov.br/home $i$

${ }^{2}$ Disponível em: https://www.grow.com.br/
} 
VIII Congresso Brasileiro de Informática na Educação (CBIE 2019)

Anais do XXX Simpósio Brasileiro de Informática na Educação (SBIE 2019)

lavras e/ou jogos lógicos (dialética) [Avanço and Lima 2011]. No século XVI, os colégios de ordem jesuítica foram os primeiros a colocar os jogos na sala de aula e a utilizá-los como recurso didático [Cunha 2012].

Para Mattar (2010), devemos levar em consideração novos estilos de aprendizagem, pois o aprendizado baseado em jogos digitais está fundamentado em duas premissas: primeira, os aprendizes mudaram em diversos pontos essenciais; segunda, são de uma geração que experenciou profundamente enquanto crescia, pela primeira vez na história, uma forma radicalmente nova de jogar. Por conta disso, teorias que formulamos no passado, sobre como as pessoas pensam e aprendem, pode não se aplicar mais. Ou seja, os métodos tradicionais de aprendizado podem não ser tão efetivos hoje, em comparação no passado [Mattar 2010].

\section{O Jogo Perfil}

"Perfil" é um jogo de tabuleiro de teste de conhecimentos e de capacidade de dedução, criado pela $\mathrm{GROW}^{\complement}{ }^{\complement}$. São utilizadas centenas de cartas com 20 dicas sobre uma pessoa, lugar, "coisa" ou ano. O jogo funciona da seguinte maneira:

1. No tabuleiro, o jogador, do momento, escolherá um número de 1 a 20.

2. Quem possuir a carta deverá falar a dica escolhida;;

3. Se o jogador souber, ganha a rodada e anda o número de dicas correspondente às dicas que sobraram no tabuleiro. Se não souber, passa a vez para o próximo, que escolhe outra dica, e assim sucessivamente.

4. Ganhará o jogo quem primeiro chegar ao final do tabuleiro, que possui um número de casas. A depender da versão.

Devido à popularidade desse jogo, algumas estratégias de ensino já foram aplicadas, sendo relatadas a seguir:

\subsection{Adaptações do Jogo "Perfil"}

Com o intuito de conhecer experiências no aprendizado utilizando o jogo "Perfil", adaptado na sala de aula, procurou-se artigos de relatos da aplicação desse jogo, especificamente, descritos na sequência.

O jogo "Química: um palpite inteligente" [Craveiro et al. 1993] é um dos pioneiros dessa abordagem no ensino de Química. O objetivo do jogo é auxiliar no aprendizado permitindo a identificação de um elemento ou composto orgânico, através da formação do seu perfil, que segue montando progressivamente, à medida que as características do objetos de estudo em questão são reveladas pelas respostas das "dicas". Os participantes devem anotar todos os dados revelados durante a formação do perfil para melhor fixar o aprendizado.

Já o jogo "Perfil Químico" [Romano et al. 2017] utiliza a tabela periódica como tabuleiro e cartas, com as características e dicas do componente químico, elaboradas de acordo com o jogo perfil. Os autores aplicaram o jogo e indicam que $76 \%$ dos alunos afirmaram que a estratégia auxiliou na compreensão do conceito sobre os elementos da tabela periódica e suas características.

As estratégias encontradas indicam satisfação dos alunos com a abordagem e boa avaliação dos professores. Entretanto, percebe-se que são adaptações não-digitais e limitadas ao conteúdo de Química. Além disso, recentemente, foi lançada a versão digital do 
VIII Congresso Brasileiro de Informática na Educação (CBIE 2019)

Anais do XXX Simpósio Brasileiro de Informática na Educação (SBIE 2019)

jogo ${ }^{3}$, mas, assim como o jogo clássico, não há possibilidade de personalização, como cadastrar as próprias dicas, por exemplo. Dessa maneira, o diferencial do presente trabalho é a inspiração no jogo clássico para criação de um jogo digital, adaptável a qualquer disciplina, feita pelo próprio professor e com opções de registro e acompanhamento, isto é, facilitando a avaliação feita pelo professor tornando lúdico ao aluno. Na próxima Seção é detalhado o método de desenvolvimento e as tecnologias usadas na implementação do "Apolo".

\section{Apolo: Concepção e Desenvolvimento}

Após verificação dos trabalhos relacionados, observa-se que as regras dos jogos desenvolvidos foram adaptadas para serem aplicadas na sala de aula. Neste trabalho as regras também sofreram ajustes, conforme mostra a Tabela 1.

Tabela 1. Adaptação das Regras do Jogo

\begin{tabular}{|l|l|}
\hline Regras do Jogo Clássico & Regras no Apolo \\
\hline Cada carta tem 20 dicas & $\begin{array}{l}\text { Não temos cartas, mas sim desafios. Cada desafio } \\
\text { pode ter de 4 a 10 dicas }\end{array}$ \\
\hline $\begin{array}{l}\text { O jogador avança as casas do tabuleiro conforme } \\
\text { o acerto das dicas. Quanto menos dicas ele tem, } \\
\text { mais casas avança }\end{array}$ & $\begin{array}{l}\text { O jogador não avança casas ao acertar. Quantos } \\
\text { menos dicas ele precisar, maior a pontuação que } \\
\text { varia de 100 até 30 pontos }\end{array}$ \\
\hline O jogador pode palpitar a partir da dica 1 & $\begin{array}{l}\text { O jogador ganha as duas primeiras dicas sem per- } \\
\text { der pontos e pode palpitar a partir da dica 3 }\end{array}$ \\
\hline Ao errar, a resposta correta é revelada & $\begin{array}{l}\text { A resposta correta não é revelada, com o intuito } \\
\text { de ser corrigida junto com o professor na sala de } \\
\text { aula }\end{array}$ \\
\hline
\end{tabular}

Além da adaptação das regras, destaca-se aqui a característica do tabuleiro, que é um jogo clássico, jogado em grupo. No entanto, houve demanda dos professores, que atuaram na concepção do Apolo, para fins de registro de avaliação. Seria importante a pontuação individual e, por isso, o Apolo é jogado individualmente, em sua concepção original. Os jogadores iniciam com 100 pontos e a cada dica usada, a pontuação é decrementada em 10 pontos. No entanto, conforme descrito nas próximas Seções, percebe-se que o professor pode adaptar para jogos em duplas ou trios na versão atual, podendo este ser indicado nos trabalhos futuros a inclusão do módulo, para jogo em grupo.

Destaca-se também que, como o jogo clássico não é voltado ao ensino, não há registro formal de acertos ou erros. Comparando-se ao Apolo, este provê relatórios de atividades tanto para os alunos, quanto para os professores que acompanham a turma, conforme detalhado nas próximas Seções.

\subsection{Desenvolvimento}

O jogo foi desenvolvido baseado em Progressive Web App (PWA), uma metodologia de desenvolvimento, que torna a experiência de uso de uma página web pelo celular semelhante a de um aplicativo mobile. Este pode ser visto como uma evolução híbrida entre as páginas da web regulares (ou sites) e um aplicativo móvel, tendo como características:

\footnotetext{
${ }^{3}$ Disponível em ihttp://www.growgames.com.br/Jogos/Perfil $\underset{\mathcal{C}}{ }$
} 
VIII Congresso Brasileiro de Informática na Educação (CBIE 2019)

Anais do XXX Simpósio Brasileiro de Informática na Educação (SBIE 2019)

possibilidade de uso offline; notificações via push e sincronização em segundo plano; além da disponibilidade de uso em diferentes dispositivos [Biørn-Hansen et al. 2017].

PWA foi escolhida pela facilidade de uso nas escolas, por exemplo, em sala de aula se adapta para uso nos celulares ou tablets dos alunos (independente do sistema operacional), nas lousas interativas ou até mesmo em computadores convencionais, ou seja, em qualquer dispositivo que tenha um navegador web compatível. Os recursos de desenvolvimento adotados foram Ionic, Firebase e GitHub Pages. O Ionic ${ }^{4}$ é um Kit de Desenvolvimento de Software gratuito que permite o criação de aplicativos móveis de qualidade com bom desempenho usando linguagens familiares da Web (HTML, CSS e JavaScript).

O armazenamento de dados da aplicação utiliza o Firebase ${ }^{5}$, na versão gratuita. Entre as vantagens estão a possibilidade de análise em tempo real sobre o comportamento dos usuários, além do sincronismo dos dados entre aplicação e usuários utilizando o banco de dados hospedado na nuvem. Para disponibilização aos usuários, foi hospedado no serviço GitHub Pages ${ }^{6}$ e está disponível para testes no endereço <https://marcussh.github.io/apolo>, além do código fonte disponibilizado em <https: //github.com/marcussh/apolo>.

Conforme já mencionado, o jogo é responsivo, ou seja, se adapta a diferentes tamanhos de tela e dispositivos. A Figura 1 mostra as telas inicias do aplicativo. A primeira tela é com o personagem e nome do jogo, posteriormente é carregada a tela com os campos para preenchimento do nome e da matrícula do aluno. Não é feita nenhuma autenticação nesse momento, pois a aplicação está em fase de testes, os campos somente captam os dados do aluno. É necessário preencher os dois campos para o botão "Entrar" ser ativado. Após essa tela, é listado as matérias para o jogador escolher.

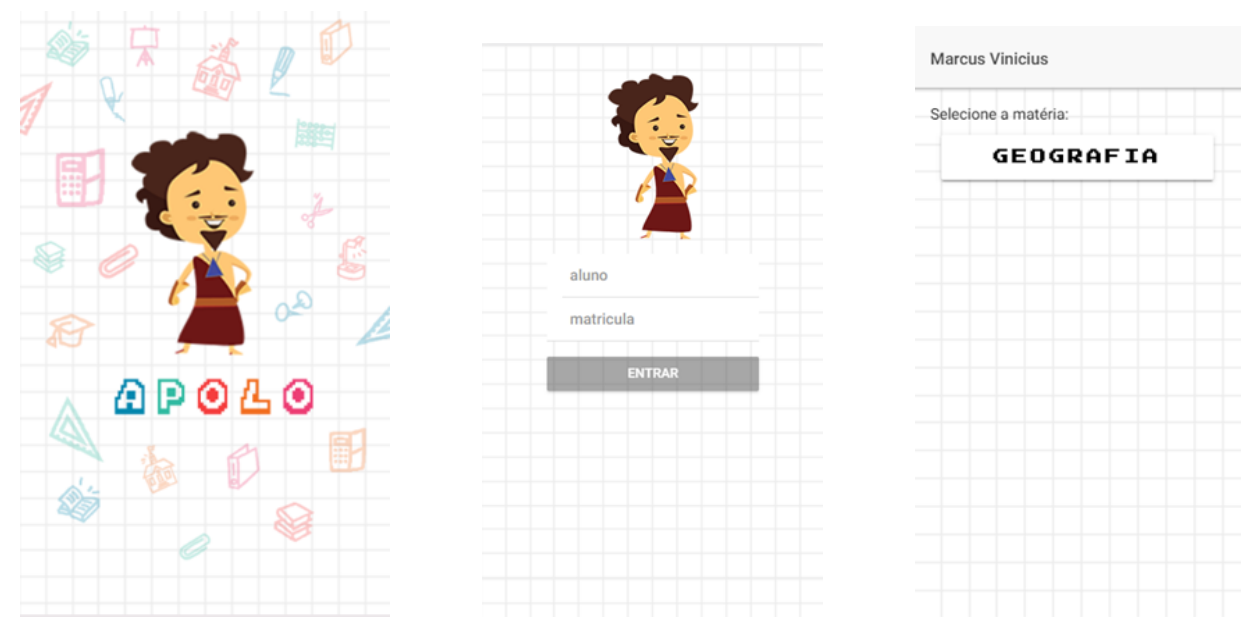

Figura 1. Telas iniciais da aplicação

Ao selecionar a matéria, a página é redirecionada para a lista de desafios que mostra os desafios da matéria que foi selecionada anteriormente e o status que indica se o desafio já foi feito ou não, conforme exibido na Figura 2. Na barra superior é mostrada a

\footnotetext{
${ }^{4}$ Disponível em $;$ https://ionicframework.com/i

${ }^{5}$ Disponível em ¡https://firebase.google.com/i

${ }^{6}$ Disponível em ¡https://pages.github.com/i
} 
VIII Congresso Brasileiro de Informática na Educação (CBIE 2019)

Anais do XXX Simpósio Brasileiro de Informática na Educação (SBIE 2019)

pontuação do jogador, em destaque na cor azul, e o botão "Sair" que finaliza a sessão do jogador. Para o professor, é possível ver listado todos os alunos que jogaram e a pontuação total de cada um. Ao selecionar um aluno é mostrado o relatório do aluno, em que mostra a pontuação de cada desafio, exibido na segunda tela da Figura 2.
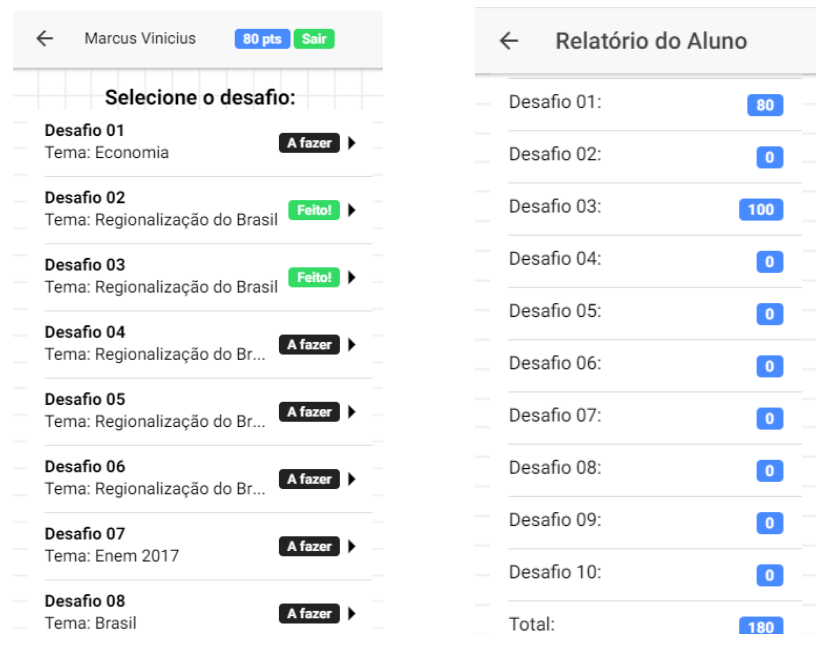

Figura 2. Telas de relatório e acompanhamento

A Figura 3 mostra tela principal do jogo em que são exibidas as dicas do desafio. Nas duas primeiras dicas o botão responder não é ativado, pois são "dicas extras". Ao avançar as dicas, o botão "Responder" da dica anterior é ocultado. Por exemplo, se o jogador visualizou a dica 4 e tinha a opção de responder o desafio, porém ele avançou para a dica 5, quando ele retornar para a dica 4, o botão para responder não estará mais visível, pois a pontuação segue a regra de que quanto menos dicas o jogador precisar, maior a pontuação.

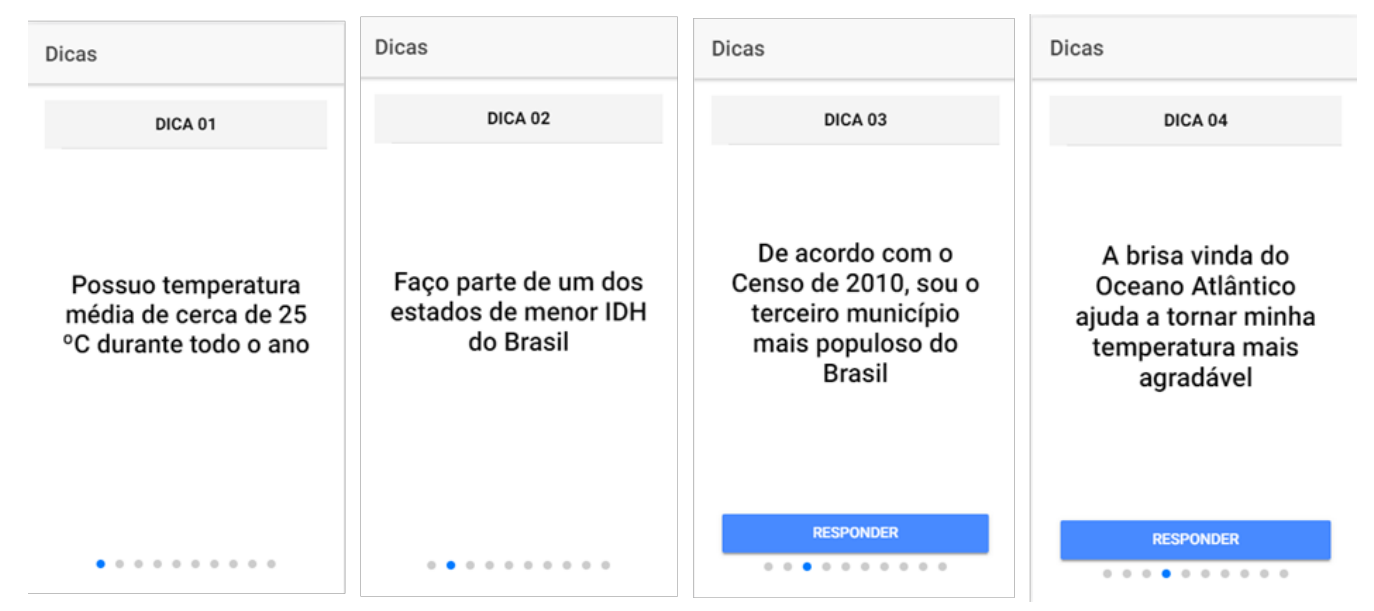

Figura 3. Telas com as dicas do jogo

Quando o jogador está pronto para responder, ele seleciona o botão "Responder" e é aberta uma caixa para ele digitar a resposta. O sistema verifica a resposta, em que é validado o que o jogador digitou e a resposta que está no banco de dados. Não há problema se a resposta for digitada em letras maiúsculas ou minúsculas, porém se houver erros 
VIII Congresso Brasileiro de Informática na Educação (CBIE 2019)

Anais do XXX Simpósio Brasileiro de Informática na Educação (SBIE 2019)

ortográficos o sistema não identifica e é considerado errado. Após o jogador responder o desafio é mostrada a tela informando se ele acertou ou errou, conforme ilustra a Figura 4. Ao clicar em voltar, a página é redirecionada para a lista de desafios.
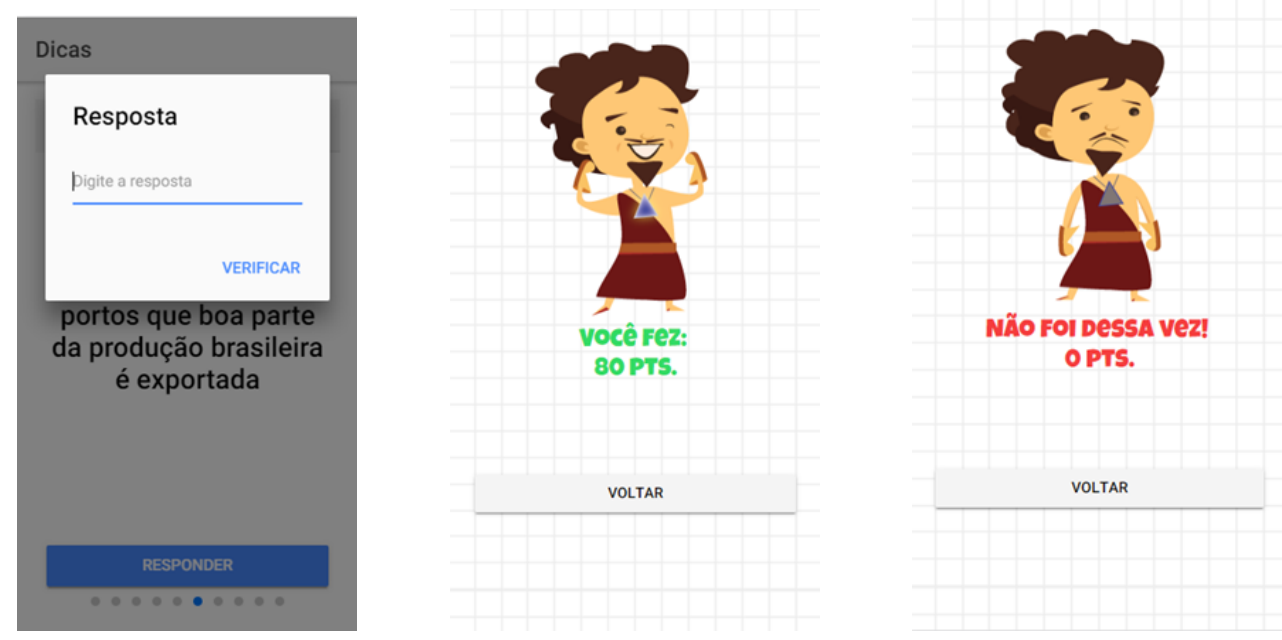

Figura 4. Telas de resposta e feedback ao usuário

Atualmente a aplicação contém apenas desafios para a disciplina de Geografia, devido suporte recebido pelos professores parceiros no desenvolvimento. Esse estudo de caso é detalhado a seguir.

\subsection{Estudo de Caso}

Para validação da proposta, procurou-se professores parceiros, interessados em testar em suas salas de aula. Dessa maneira, um professor de Geografia aceitou participar do estudo de caso. Para elaboração dos desafios na área de Geografia, alunos de licenciatura contribuíram e as questões foram corrigidas e validadas pelo professor, que além da formação em Geografia é especialista em Gestão Escolar e atualmente é Coordenador Pedagógico no Instituto Federal de Brasília. Ao todo, foram criados 8 desafios que estavam diretamente vinculados ao conteúdo trabalhado pelo professor em sala de aula. A seguir, apresentam-se dicas para um desafio que espera como resposta "Democracia":

1. Sou um conceito

2. No pensamento de Jurgen Habermas eu sou construído a partir de uma dimensão procedimental, calcada no discurso e na deliberação

3. Uma condição para que eu aconteça é o debate livre e racional entre cidadãos e estado

4. Posso favorecer processos de inclusão social, segundo Jurgen Habermas

5. Para que eu seja legítimo, o processo de tomada de decisões políticas precisa ocorrer a partir de uma ampla discussão pública, para somente então decidir

6. O filósofo Platão falou muito sobre mim

7. Hans Kelsen, juiz da Corte Suprema dos EUA, disse isso sobre um dos meus elementos essenciais: "A cabine eleitoral é o templo das instituições americanas, onde cada um de nós é um sacerdote, ao qual é confiada a guarda da aliança e cada um oficia do seu próprio altar"

8. Apareço bastante nos tempos de eleições 
VIII Congresso Brasileiro de Informática na Educação (CBIE 2019)

Anais do XXX Simpósio Brasileiro de Informática na Educação (SBIE 2019)

9. Os meus princípios são: a liberdade individual, a liberdade de expressão, a igualdade de direitos políticos

Assim, o jogo foi aplicado em uma turma do $2^{\circ}$ ano do Ensino Médio. A aplicação do jogo foi acompanhada pelo professor parceiro. As regras foram explicadas e os alunos passaram a responder os oito desafios propostos. Após a aplicação, os alunos responderam um questionário que teve como objetivo registrar o nível de interesse deles pela proposta.

O questionário tinha oito questões: (1) O uso do jogo favoreceu a minha aprendizagem na disciplina?; (2) Eu já conhecia o conteúdo que estava no jogo?; (3) Como você classifica o nível de dificuldade dos desafios?; (4) Em uma escala de 1 a 5, em que 5 é o nível máximo, qual o seu nível de interesse em aprender com o jogo?;(5) Você jogaria novamente com conteúdo de outras disciplinas?; (6) Você aprendeu algo novo com o jogo?; (7) Você acredita que a relação com o professor melhora com o uso do jogo como ferramenta de aprendizagem?; (8) O jogo reforçou os seus conhecimentos? A próxima Seção sintetiza os resultados preliminares obtidos a partir desse estudo de caso.

\section{Resultados Preliminares}

Conforme já mencionado, realizou-se estudo de caso em uma turma. De maneira qualitativa, percebeu-se maior engajamento dos alunos durante aplicação da atividade. $\mathrm{O}$ professor parceiro avaliou como positiva a dinâmica e sugeriu melhorias para o jogo. Por exemplo, apesar do módulo ser individual, alguns alunos ficaram interessados em discutir e/ou solicitar a opinião dos colegas que estavam ao lado. Por isso, observou-se que dependendo da estratégia do professor, é possível jogar em duplas ou trios, mas é interessante que seja adicionado um módulo para identificação dos integrantes do grupo.

Outra questão levantada é que a resposta seja vista pelo aluno, não no momento do jogo, mas após o professor fazer correção em sala e liberar pelo módulo administrador, visto que o jogo pode ser utilizado como revisão para avaliações, como provas e testes. Além destas, o professor também sugeriu que as questões criadas pelos professores fiquem compartilhadas, como uma base de questões, assim é possível compartilhar em outras escolas e até mesmo permitir o uso por outros professores, favorecendo a troca entre os docentes também.

Quanto aos alunos, vinte e cinco alunos participaram da pesquisa e responderam o questionário. Conforme ilustrado na Figura 5, para $84 \%$ dos alunos, o uso do jogo favoreceu a aprendizagem na disciplina e $72 \%$ deles responderam que aprenderam algo novo com o jogo.

Quando perguntados se jogariam novamente com conteúdo de outra disciplina, $92 \%$ dos alunos não hesitaram em responder que sim, o que mostra o quão satisfeitos ficaram com a experiência. Além disso, $72 \%$ indicou que o jogo reforçou seus conhecimentos na disciplina, conforme apresentado na Figura 6.

Além dos resultados exibidos em gráficos, os alunos indicaram que gostaram do nível de dificuldade do jogo. No entanto, essa é uma atividade controlada pelo professor, visto que ele criará as dicas para cada desafio e pode torná-los mais fáceis ou difíceis, conforme seus critérios pedagógicos. 


\section{O USO DO JOGO FAVORECEU A MINHA APRENDIZAGEM NA DISCIPLINA?}

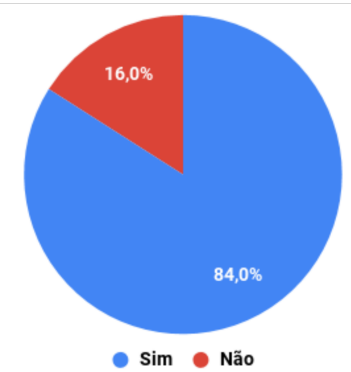

VOCÊ APRENDEU ALGO NOVO COM O JOGO?

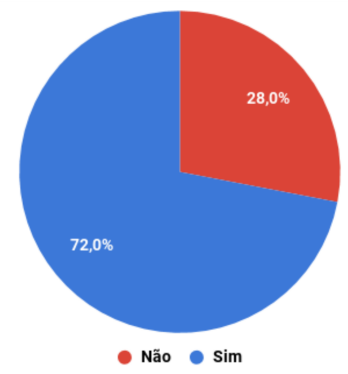

Figura 5. Questões respondidas pelos alunos participantes do estudo

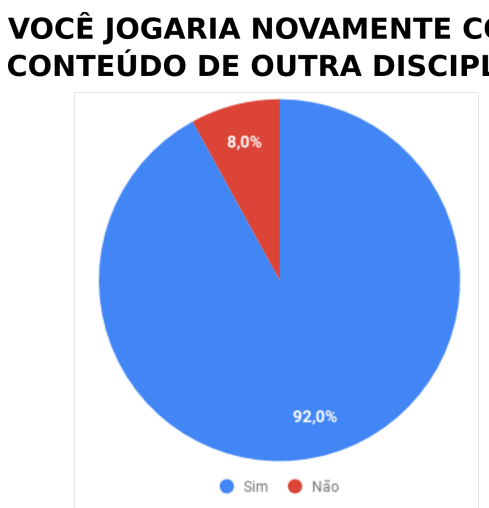

\section{O JOGO REFORÇOU OS SEUS CONHECIMENTOS?}

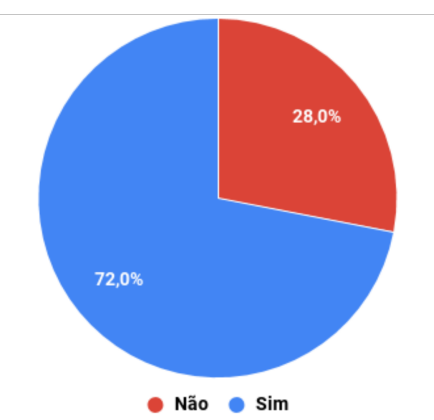

Figura 6. Satisfação dos alunos pela atividade

\section{Considerações Finais}

O uso do jogo como meio de aprendizagem surgiu há séculos e até os dias atuais tem surtido efeitos positivos quando associado à educação, pois desperta no aprendiz a descoberta de suas habilidades, através da dinâmica que o jogo tem em si. O advento da tecnologia favoreceu ainda mais a proximidade do jogo e educação, inovando a forma de como o conteúdo é absorvido para quem está aprendendo. A tecnologia trouxe recursos em que é possível utilizá-los para a transmissão e compartilhamento de conteúdo. Além disso, há projetos do Ministério da Educação que incentivam a criação de ferramentas para apoio ao ensino, inclusive com possibilidade de envio para a plataforma de recursos educacionais de maneira facilitada.

Dessa maneira, este trabalho apresentou a criação de um jogo digital inspirado no jogo de tabuleiro "Perfil". O objetivo do jogo é apoiar o ensino em sala de aula de forma lúdica e proporcionar maior interesse dos alunos. O diferencial da aplicação está na possibilidade de personalização pelo professor, além do acompanhamento dos alunos, contribuindo para avaliação formativa da turma.

Para validação, houve um estudo de caso em uma turma de Ensino Médio, dentro da disciplina de Geografia. A avaliação positiva pelo professor e o interesse dos alunos na atividade mostram que o objetivo foi alcançado e que a ferramenta se mostra com potencial para fortalecer os recursos educacionais digitais para o ensino básico brasileiro. Como limitações, percebe-se a falta de um módulo para jogo em duplas ou trios e a possibilidade de exibir as respostas para os alunos após conclusão da atividade. 
VIII Congresso Brasileiro de Informática na Educação (CBIE 2019)

Anais do XXX Simpósio Brasileiro de Informática na Educação (SBIE 2019)

Os trabalhos futuros indicam a continuidade do desenvolvimento, a fim de incluir os módulos sugeridos e aperfeiçoar a usabilidade da interface gráfica. Também, pretendese realizar novos estudos de caso com outros professores e em diferentes turmas, não apenas no Ensino Médio.

\section{Referências}

Avanço, L. D. and Lima, J. M. d. (2011). Jogo e educação no contexto da república platônica: Algumas reflexões.

Biørn-Hansen, A., Majchrzak, T. A., and Grønli, T.-M. (2017). Progressive web apps: The possible web-native unifier for mobile development. In WEBIST, pages 344-351.

BRASIL. Ministério da Educação. Secretaria de Educação Média e Tecnológica (2002). Pcn+ ensino médio: orientações educacionais complementares aos parâmetros curriculares nacionais-ciências da natureza, matemática e suas tecnologias.

CNME (2019). Centro nacional de mídias da educação. http: / / cnme. mec .gov . br/o-que-e/. Acessado: 2019-06-25.

Craveiro, A. A., Craveiro, A. C., Bezerra, F. G. d. S., and Cordeiro, F. (1993). Química: um palpite inteligente. Química Nova, 16(3):234-236.

Cunha, M. B. d. (2012). Jogos no ensino de química: considerações teóricas para sua utilização em sala de aula. Química Nova na Escola, São Paulo,[s. L.], 34(2):92-98.

Mattar, J. (2010). Games em educação. Pearson Educación.

PNAD (2018). Pesquisa nacional por amostra de domicílios contínua: Educação 2017. https://bit.1y/2INZn7Y. Acessado: 2019-01-15.

Rogers, C. R., da Mata Machado, E. d. G., and de Andrade, M. P. (1972). Liberdade para aprender: uma visão de como a educação deve vir a ser. Interlivros de Minas Gerais.

Romano, C. G., Carvalho, A. L., Mattano, I. D., Chaves, M., and Antoniassi, B. (2017). Perfil químico: um jogo para o ensino da tabela periódica. Revista Virtual de Química, 9(3):1235-1244.

Ryan, R. M. and Deci, E. L. (2000). Self-determination theory and the facilitation of intrinsic motivation, social development, and well-being. American psychologist, 55(1):68. 